\title{
CONSTIPATION IS INDEPENDENTLY ASSOCIATED WITH DELIRIUM IN CRITICALLY ILL VENTILATED PATIENTS
}

Roland Smonig ${ }^{\mathrm{a}}, \mathrm{MD}$; Timothée Wallenhorst ${ }^{\mathrm{ac}}, \mathrm{MD}$; Pierre Bouju ${ }^{\mathrm{ac}}, \mathrm{MD}$; Julien Letheulle ${ }^{\mathrm{a}}$

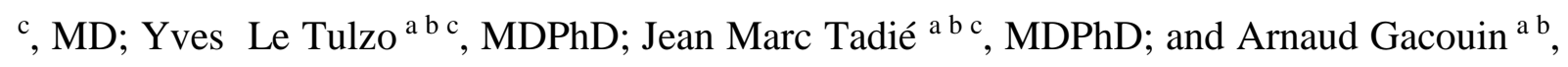
MD.

${ }^{a}$ CHU Rennes, Maladies Infectieuses et Réanimation Médicale, F-35033 Rennes, France

${ }^{\mathrm{b}}$ Inserm-CIC-F-35043 Rennes, France

${ }^{\mathrm{c}}$ Univ Rennes 1, Faculté de Médecine, Biosit, F-35043 Rennes, France

Phone: 33299284248

Fax 33299284164

Corresponding author: A. Gacouin

E-mail: arnaud.gacouin@chu-rennes.fr

Setting for the study: Service de Réanimation Médicale, Hôpital Pontchaillou, CHU Rennes. Financial support used for the study: none.

Words count for text: 501

The investigators declare that they have no conflicts of interest related to this manuscript, that they have full control of all of the primary data, and that they agree to allow the journal to review their data if requested. 
Substantial contributions to the conception or design of the work or the acquisition, analysis, or interpretation of data were made by RS, TW, PB, JL, JMT and AG.

The work was drafted or critically revised for important intellectual content by RS, YLT, JMT and AG; AND

Final approval of the version to be published: RS, TW, PB, JL, YLT, JMT and AG

Key words: constipation; delirium; critical care; observational study; mechanical ventilation.

\section{Dear Editor,}

Delirium is a central nervous system (CNS) dysfunction reported in up to $80 \%$ of intensive care unit (ICU) patients associated with negative short and long-term outcomes $(1,2)$. Gastrointestinal motility disorders are frequent in ICU patients leading to frequent delayed passage of stools (3). Because there is a bi-directional communication between the CNS and the digestive tract (4), we believed it relevant to test the hypothesis that constipation and delirium are related in ICU patients.

The aims of this study were 1) to determine if delayed passage of stools was independently associated with the development of delirium in mechanically ventilated patients and 2) to identify which delay in the passage of stools had the best discrimination capacity to predict delirium. For that purpose, we performed a prospective observational cohort study between May 1, 2013 and April 31, 2014. The study was previously approved by the hospital's Institutional Review Board. Patients with mechanical ventilation (MV) duration of 2 days or more were eligible for the study if they were 18 years of age or older, were expected to be free of delirium, had been placed under MV less than 24 hours before admission to the ICU, and had an ICU of 4 days or more. Constipation management was not protocolized. All patients received a selective decontamination of the digestive tract with a solution containing polymyxin 
E, tobramycin and amphotericin B. Patient sedation status was evaluated using the Richmond Agitation Sedation Scale (RASS) and the protocol did not include a systematic daily interruption. The presence of delirium was assessed using the Confusion Assessment Method for the ICU (CAM-ICU) (5). Delirium status was determined twice daily by a trained ICU nurse or a research-physician. Delirium was defined as two consecutive days testing positive on the CAM-ICU. Stool production was assessed daily by nurses in our ICU who routinely used a semi quantitative tool for scoring.

During the 12 months of the study, 1052 patients were admitted at our ICU, 168 were assessed for delirium, and delirium was documented in 105 (62.5\%) patients (Supplementary Fig.1). Baseline characteristics did not differ significantly between patients with and without delirium (Supplementary Table 1). The median delay until first bowel movement was 5 days, while the median delay until the diagnosis of delirium was 7 days. Delay in passage of stools, duration of MV before being assessable for delirium and duration of treatment with benzodiazepines were the variables found to be independently associated with delirium (Table 1). The area under receiver-operating characteristic curve of delay in passage of stools $(0.76)$ was significantly higher than duration of treatment with benzodiazepines $(0.65, \mathrm{p}=0.03)$ and duration of MV (0.64, p=0.04) (Supplementary Fig 2) and the most discriminative cut-off point was 5 days for delay in passage of stools.

In conclusion, this is the first report to suggest that there is an independent association between constipation and delirium in ventilated ICU patients and that the likelihood of delirium increased after the fifth day of an ICU stay without bowel movements 


\section{References}

1. Barr J, Fraser GL, Puntillo K, Ely EW, Gelinas C, Dasta JF, Davidson JE, Devlin JW, Kress JP, Joffe AM, Coursin DB, Herr DL, Tung A, Robinson BR, Fontaine DK, Ramsay MA, Riker RR, Sessler CN, Pun B, Skrobik Y, Jaeschke R (2013) Clinical practice guidelines for the management of pain, agitation, and delirium in adult patients in the intensive care unit. Crit Care Med 41: 263-306

2. Pandharipande PP, Girard TD, Jackson JC, Morandi A, Thompson JL, Pun BT, Brummel NE, Hughes CG, Vasilevskis EE, Shintani AK, Moons KG, Geevarghese SK, Canonico A, Hopkins RO, Bernard GR, Dittus RS, Ely EW (2013) Long-term cognitive impairment after critical illness. N Engl J Med 369: 1306-1316

3. Gacouin A, Camus C, Gros A, Isslame S, Marque S, Lavoue S, Chimot L, Donnio PY, Le Tulzo Y (2010) Constipation in long-term ventilated patients: associated factors and impact on intensive care unit outcomes. Crit Care Med 38: 1933-1938

4. Mayer EA (2011) Gut feelings: the emerging biology of gut-brain communication. Nat Rev Neurosci 12: 453-466

5. Gusmao-Flores D, Salluh JI, Chalhub RA, Quarantini LC (2012) The confusion assessment method for the intensive care unit (CAM-ICU) and intensive care delirium screening checklist (ICDSC) for the diagnosis of delirium: a systematic review and meta-analysis of clinical studies. Crit Care 16: R115 
Table 1: Unadjusted and adjusted analysis for variables associated with delirium

\begin{tabular}{|c|c|c|c|c|c|c|}
\hline \multirow[t]{2}{*}{ Variables } & \multicolumn{3}{|c|}{ Unadjusted analysis } & \multicolumn{2}{|c|}{ Adjusted analysis } & \multirow[b]{2}{*}{$\mathrm{P}$ value } \\
\hline & HR & $95 \% \mathrm{CI}$ & $\mathrm{P}$ value & HR & $95 \% \mathrm{CI}$ & \\
\hline Delay in passage of stools (1-day increment) & 1.05 & $0.99-1.10$ & 0.06 & 1.14 & $1.06-1.12$ & $<0.01$ \\
\hline Delay in nutrition (1-day increment) & 0.98 & $0.99-1.02$ & 0.69 & & & \\
\hline Delay in laxatives (1-day increment) & 1.01 & $0.96-1.06$ & 0.67 & & & \\
\hline Abdominal distension & 1.23 & $0.87-1.90$ & 0.23 & & & \\
\hline Age $>60$ years & 1.23 & $0.84-1.80$ & 0.29 & & & . \\
\hline Male & 1.16 & $0.79-1.72$ & 0.45 & & & \\
\hline \multicolumn{7}{|l|}{ Severity } \\
\hline SAPS II (1-point increment) & 1.01 & $0.99-1.02$ & 0.35 & & & \\
\hline SOFA score on day 1 of MV (1-point increment) & 1.01 & $0.96-1.06$ & 0.82 & & & \\
\hline Charlson comorbidity index score (1-point increment) & 1.05 & $0.96-1.14$ & 0.31 & & & \\
\hline \multicolumn{7}{|l|}{ Baseline risk factors ICU delirium } \\
\hline History of hypertension & 0.89 & $0.60-1.3$ & 0.56 & & & . \\
\hline At-risk drinking & 1.08 & $0.70-1.67$ & 0.76 & & & \\
\hline Home use of benzodiazepines & 1.64 & $1.08-2.50$ & 0.02 & 1.27 & $0.83-1.94$ & 0.28 \\
\hline Current smoking & 1.21 & $0.78-1.86$ & 0.39 & & & \\
\hline Liver cirrhosis, $\mathrm{n}(\%)$ & 1.10 & $0.42-1.61$ & 0.56 & & & \\
\hline
\end{tabular}


Duration of MV (1-day increment)

Corticosteroid administration

Duration of benzodiazepines (1-day increment)

Duration of morphine (1-day increment)

Duration of propofol (1-day increment)

Potential contributors to ICU delirium, n (\%)

Severe sepsis or septic shock

hyponatremia $<125 \mathrm{mmol} / \mathrm{L}$

One episode or more of hypoglycaemia $<2.2 \mathrm{mmol} / \mathrm{L}$

One episode or more of $\mathrm{SpO} 2<89 \%$ during at least $30 \mathrm{mn}$

Length of ICU stay before first chair (1-day increment)

$\begin{array}{llllll}1.30 & 1.22-1.40 & <0.01 & 1.47 & 1.32-1.64 & 0.01 \\ 0.99 & 0.62-1.35 & 0.63 & & & \cdot \\ 1.06 & 1.01-1.12 & 0.02 & 1.09 & 1.01-1.18 & 0.03 \\ 1.02 & 0.99-1.10 & 0.12 & & & \\ 1.01 & 0.95-1.05 & 0.93 & & & \\ & & & & \\ 0.98 & 0.59-1.30 & 0.51 & & \\ 1.03 & 0.55-1.93 & 1.65 & & \\ 0.60 & 0.19-1.91 & 0.39 & & \\ 0.88 & 0.65-1.20 & 0.42 & & \\ 1.02 & 0.93-1.12 & 0.69 & & \end{array}$

SAPS, Simplified Acute Physiologic Score; SOFA, Sequential Organ Failure Assessment; CAM-ICU, Confusion Assessment Method for the Intensive Care Unit; MV, mechanical ventilation. 